\title{
Mitosin/CENP-F in mitosis, transcriptional control, and differentiation
}

\author{
Li Ma ${ }^{1,2}$, Xiangshan Zhao $^{1} \&$ Xueliang Zhu ${ }^{1, *}$ \\ ${ }^{1}$ Laboratory of Molecular Cell Biology, Institute of Biochemistry and Cell Biology, Shanghai Institutes for \\ Biological Sciences, Chinese Academy of Sciences, Shanghai, 200031, China; ${ }^{2}$ Graduate School of Chinese \\ Academy of Sciences, Beijing, 100039, China
}

(ㄷ) 2006 National Science Council, Taipei

Key words: differentiation, kinetochore, mitosis, transcription

\begin{abstract}
Summary
Mitosin/CENP-F is a large nuclear/kinetochore protein containing multiple leucine zipper motifs potentially for protein interactions. Its expression levels and subcellular localization patterns are regulated in a cell cycle-dependent manner. Recently, accumulating lines of evidence have suggested it a multifunctional protein involved in mitotic control, microtubule dynamics, transcriptional regulation, and muscle cell differentiation. Consistently, it is shown to interact directly with a variety of proteins including CENP-E, NudE/Nudel, ATF4, and Rb. Here we review the current progress and discuss possible mechanisms through which mitosin may function.
\end{abstract}

Mitosin, also named CENP-F, was initially identified as a human autoimmune antigen $[1,2]$ and an in vitro binding protein of the tumor suppressor $\mathrm{Rb}[3,4]$. Its dynamic temporal expression and modification patterns as well as ever-changing spatial distributions following the cell cycle progression imply itself a multifunctional protein. Recently, growing lines of evidence have highlighted its roles in a wide variety of cellular activities, including mitotic control, microtubule (MT) dynamics, gene regulation, and muscle cell differentiation. New findings have also raised new questions to be addressed in the future.

\section{Biochemical and cytological properties}

Mitosin gene is located at human chromosome 1q32-41 [3]. It contains 19 exons and spans about $51 \mathrm{~kb}$ (Figure 1). The mRNA is more than $10 \mathrm{~kb}$ and encodes a large acidic protein of 3114 amino

*To whom correspondence should be addressed. Phone: + 8621-54921011; Fax: +86-21-54921406; E-mail: xlzhu@sibs.ac.cn acid residues (GenBank Accession No. CAH73032) [3]. The gene expression is cell cycle-dependent, as the mRNA levels increase following $\mathrm{S}$ phase progression and peak in early $M$ phase [3]. Such patterns are regulated by the Forkhead transcription factor FoxM1 [5].

Mitosin is a nuclear protein in interphase and exhibits dynamic localizations in $\mathbf{M}$ phase. In primate cells, its protein levels are cell cycledependent as well. Mitosin/CENP-F is undetectable or weakly expressed in G1. When cells were released from early G1, bulk mitosin appeared several hours after $\mathrm{Rb}$ phosphorylation [3]. Therefore, mitosin expression occurs after G1 progression through the restriction point marked by phosphorylation of $\mathrm{Rb}[6,7]$, suggesting a correlation with the $\mathrm{S}$ phase entry. Indeed, expression was seen after cells were synchronized in $\mathrm{S}$ phase [3]. The high level expression then persists till anaphase [1-3]. Such a property makes mitosin/ CENP-F a useful proliferation marker in cancer research [8-11]. Inside cells, mitosin is transiently associated with the outer kinetochore plate and 


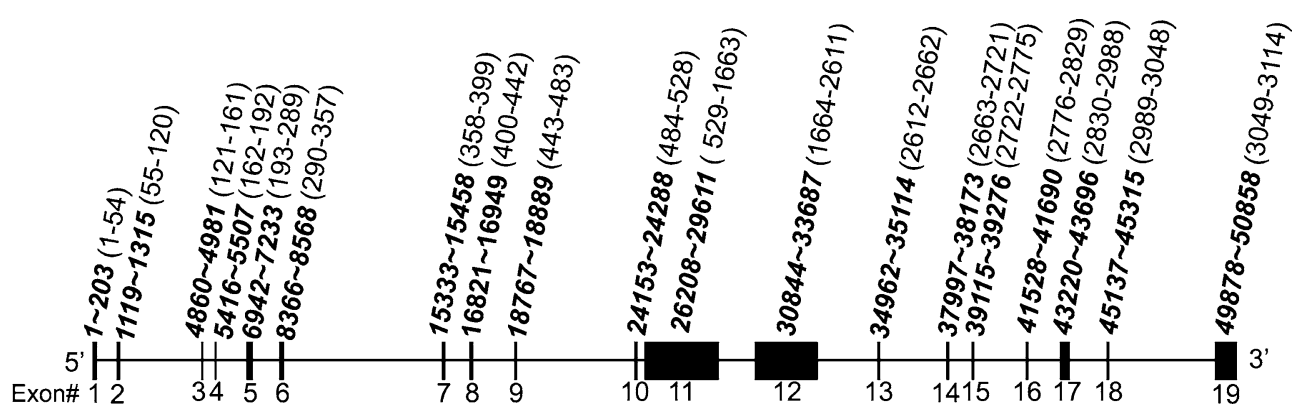

Figure 1. Structure of the human mitosin/CENP-F gene. Bold numbers indicate positions of the first and last nucleotides for exons according to a reference genomic DNA sequence (GenBank Accession No. NC_000001). The numbers in each bracket denote the first and last amino acids encoded by each exon. The lengths of exons are drawn to scale.

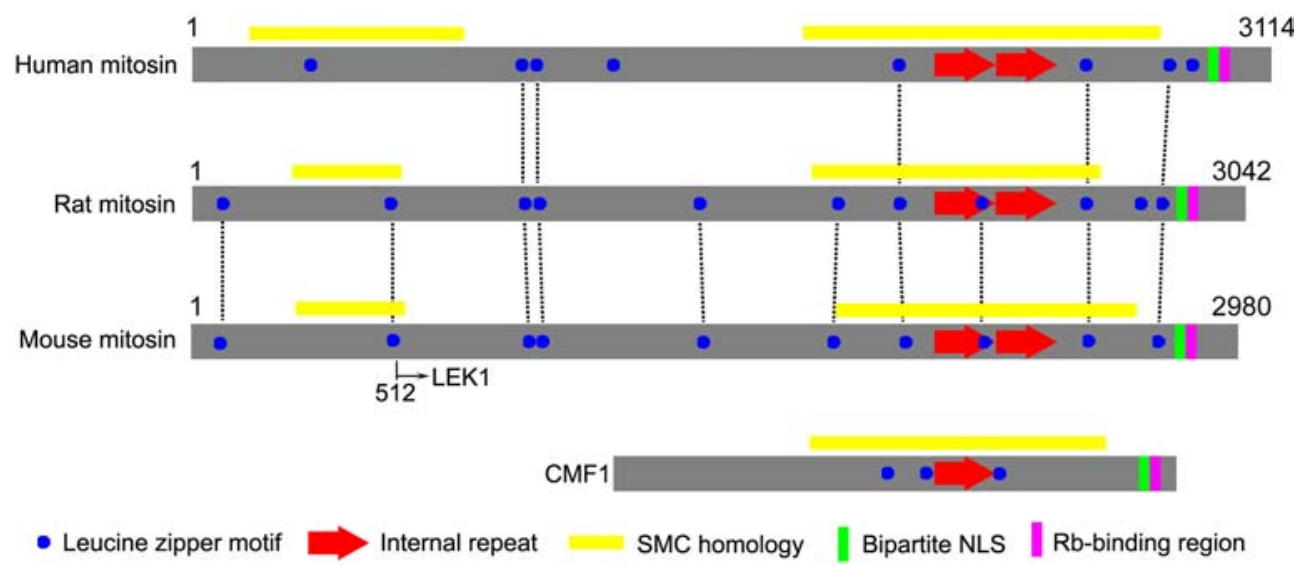

Figure 2. Schematic comparisons for mitosin orthologs. Sequences are based on GenBank accessions CAH73032 (human mitosin), XP_223060 (rat mitosin), AF194970 (LEK1), AK029517 (5' sequence for mouse mitosin), and U62026 (CMF1). The putative fulllength mouse mitosin sequence was obtained by joining AK029517 and AF194970 together. Only sequences with at least three blocks of leucine heptad repeats are considered as a zipper motif. Conserved motifs are indicated by dashed lines.

the spindle apparatus in early $M$ phase and is redistributed to the spindle midzone in anaphase and to the midbody in telophase, followed by complete degradation at the end of cell division $[1-3,12]$. It is highly phosphorylated in $\mathrm{M}$ phase [3], but whether the phosphorylation is required for its dynamic reorganizations remains unclear. In addition, mitosin/CENP-F is farnesylated at the C-terminal CAAX motif. Such a modification that is required not only for its localization to the nuclear envelope and kinetochores, but also for timely progression of cells through $\mathrm{G} 2 / \mathrm{M}$ and degradation of the protein after mitosis $[13,14]$.

Mitosin contains multiple motifs and functional domains, including a pair of highly-charged tandem repeats and eight leucine zipper motifs potentially for protein-protein interactions (Figure 2) [3, 15]. Its secondary structure is predicted to be mostly $\alpha$-helical, except for the C-terminal region of 220 residues, which is proline-rich. In addition to the CAAX motif at the extreme C-terminus [13], mitosin contains an Rb-binding domain and a bipartite nuclear localization signal (NLS) (Figure 2) [3, 12]. NCBI conserved domain search also reveals that it shares low similarities with chromosome segregation ATPase (SMC) at multiple positions (Figure 2).

Mitosin in other species has also been characterized. Its orthologs are termed LEK1 in mouse or CMF1 in chicken [16-18], though the reported sequences do not appear to be full-length (Figure 2). They share overall structural characteristics with mitosin, except that CMF1 does not contain the duplicated region (Figure 2). Divergence analysis suggests that the duplication event appears to occur after separation of bird and mammal from 
their common ancestor during evolution [19]. LEK1 targets to kinetochores [19], while such a localization has not been documented for CMF1. Moreover, their interactions with $\mathrm{Rb}$ have also been confirmed [20, 21]. Interestingly, both CMF1 and LEK1 manifest distinct expression patterns during development. CMF1 is highly expressed in differentiating chicken heart from stages 9 to 18 ; after this, the expression levels drop dramatically $[16,18]$. Its subcellular localization is also variable. In differentiating cardiac myocytes, CMF1 locates in the cytoplasm [18]. In differentiating skeletal myocytes, however, its distribution is initially in the nucleus in early myoblasts, and then in the cytoplasm [22]. LEK 1 , in contrast, is ubiquitously expressed in early mouse embryo. However, its expression is dramatically declined throughout the embryo as the overall cell proliferation slows down [17]. Furthermore, LEK1 does not seem to be cell cycle-dependent [17]. How the differences affect their physiological functions, however, still remains unclear.

\section{Mitosin is critical for proper $M$ phase progression}

The kinetochore is a three-layer organelle located at the primary constriction, or centromere, of a chromosome. Kinetochores provide sites of spindle MT attachment for proper M phase progression. There dwells a group of proteins to manage MT-related activities such as MTkinetochore interaction, kinetochore MT dynamics, and MT-based chromosome motility [23-25]. In addition, another group of proteins, for instance, Mad2, functions in the so-called "spindle checkpoint" by monitoring the status of MT attachment to guarantee proper anaphase onset, thus avoiding the disaster of genomic instability [23, 26, 27].

Kinetochore localization of mitosin is affected in several aspects. Its kinetochore targeting is conferred mainly through cooperation between an essential "core" region and the internal repeat, which appears to stabilize the interaction of the core region with kinetochores [28]. Silencing Bub1 [29], CENP-I [30], RanBP2/Nup358 [29, 31], Zwint-1 [32], or Sgt1 [33] also abolishes the kinetochore targeting of mitosin/CENP-F. Based on available information, genetic links for these proteins can be speculated (Figure 3). Which

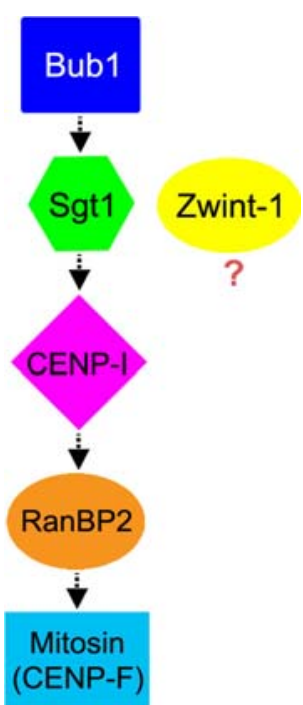

Figure 3. Possible molecular links for kinetochore targeting of mitosin/CENP-F. Bubl appears to lie most upstream and is required for kinetochore targeting of all the indicated proteins [29-31, 33, 34]. Zwint-1 is downstream of Bub1 and upstream of mitosin [32], but its relationship with other proteins is not clear. Direct interactions have not been reported among these proteins.

protein(s) directly tethers mitosin, however, is not clear. On the other hand, like many outer kinetochore proteins, mitosin is also constitutively transported from kinetochores to spindle poles along MTs by the cytoplasmic dynein/dynactin motor complex $[19,35]$. Such a translocation may potentially reduce mitosin levels at the kinetochore after MT attachment [19].

Mitosin is important for proper $\mathrm{M}$ phase progression. Silencing mitosin/CENP-F in HeLa cells expressing GFP or YFP-tagged histone 2B $(\mathrm{H} 2 \mathrm{~B})$ results in pre-anaphase delay [36-38]. Some chromosomes experience difficulties to reach the spindle midzone. After prolonged mitotic block, cells may exit $\mathrm{M}$ phase by either anaphase initiation or chromosome decondensation. Chromosome misalignment is also observed in U2OS cells knocking down mitosin/CENP-F, though anaphase is usually initiated much earlier than in HeLa cells [5]. Nevertheless, variations in mitotic behaviors exist among reports [5, 36-38]. This may be due to different repression efficiencies or incomplete depletion of the entire mitosin protein, considering the large size of mitosin mRNA. Bomont and colleagues find that the MT-kinetochore interface in CENP-F-depleted cells appears 
unstable. Mad1, which is essential for kinetochore targeting of Mad2, undergoes repeated association-dissociation cycles at the kinetochore [36]. Holt and colleagues report that silencing CENP-F weakens the adhesion between sister chromatids [38]. Therefore, in addition to efficiencies of RNAi, different cell lines or sublines might exhibit different sensitivity to these defects, accordingly manifesting variations in behavior.

Mitosin appears to play a role in correction of false MT-kinetochore connections. During prometaphase/metaphase transition, there are chances for MTs from the same pole to associate with both sister kinetochores in a chromosome to form syntelic attachment and for those from opposing poles to bind the same kinetochore to form merotelic attachment [39]. These incorrect attachments are destabilized or compromised during $M$ phase progression in intact cells [4042] but appear to persist in mitosin-depleted HeLa cells [37, 38]. Among key factors involved in the correction of false MT attachments are Aurora B kinase and the kinesin motor MCAK [42-44]. Whether mitosin is linked to these molecules remains unclear.
Mitosin-depleted HeLa cells show reduced tension across sister kinetochores in fully aligned chromosomes [36-38]. This can be just a consequence of merotelic MT attachment [37, 38]. Nevertheless, as kinetochore pairs oriented roughly in parallel with the spindle axis do not differ from the unparallel ones in their interkinetochore distances [37], attenuated functions of kinetochore motors, such as cytoplasmic dynein and CENP-E, may contribute to the tension reduction as well [23]. Mitosin/CENP-F has been shown to directly bind CENP-E, whose depletion also results in misaligned chromosomes [45-48]. Dynein is linked to mitosin through other proteins (Nudel and NudE) as well (see below). Both CENP-E and dynein are sensitive to MT attachment, probably due to their poleward transport, with CENP-E as a dynein cargo [35, 49]. Upon mitosin depletion, dynein and CENP-E are further reduced at kinetochores in MT-dependent manner, suggesting that mitosin stabilizes them against MT-dependent shedding [37]. Decreased steadystate levels of kinetochore dynein and CENP-E may thus result in reduced tension across bi-attached kinetochores.

(a)
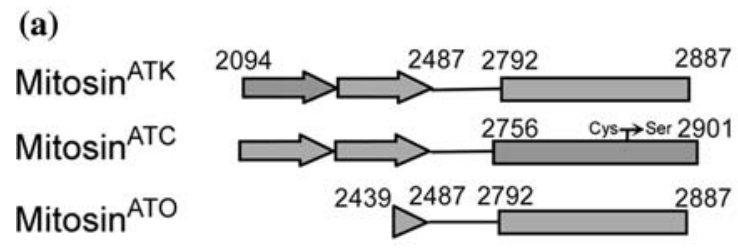

Nudel ${ }^{\mathrm{P} 1}$ Interaction $1.46 \pm 0.49+$ $0.01 \pm 0.02-$ $0.05 \pm 0.02-$

(b)

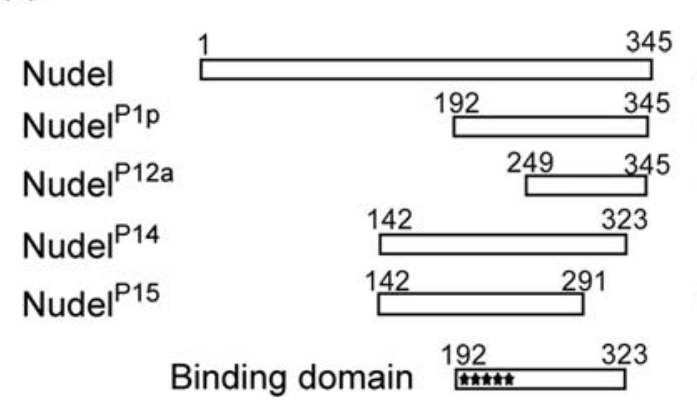

\section{Mitosin ${ }^{\text {ATK }}$ Interaction}

$2.73 \pm 0.29+$

$0.52 \pm 0.07+$

$0.06 \pm 0.01-$

$1.31 \pm 0.43+$

$0.06 \pm 0.03-$

\section{Binding domain}

Figure 4. Interaction between mitosin and Nudel in yeast two-hybrid system. (a) The kinetochore-binding regions of mitosin interact with Nudel. Schematic diagrams of different mitosin mutants are shown. The number above each diagram represents amino acid position. Mitosin ${ }^{\text {ATK }}$ is a mutant capable of efficient kinetochore localization, while mitosin ${ }^{\text {ATC }}$ contains a point mutation that disrupts the localization [28]. Nudel ${ }^{\mathrm{P} 1}$ (containing residues 142-345) is a partial polypeptide identified from a two-hybrid screen for mitosin-associated proteins. The $\beta$-galactosidase activity of each combination is shown as Mean $\pm \mathrm{SD}$. (b) Mapping for the mitosin-binding domain of Nudel. Different Nudel mutants were tested for their abilities to interact with mitosin ${ }^{\text {ATK }}$. 
Mitosin appears to function in MT dynamics as well. Mitosin-depleted cells exhibit higher incidence of spindle abnormality including multiastral and aberrant bipolar spindles [37, 38]. Recently, overexpressing a cytoplasmic form of LEK1 (cytLEK1) is shown to disorganize MT arrays in interphase $3 \mathrm{~T} 3$ cells through interaction with murine NudE [50]. NudE and its paralog Nudel (NudE-like) are dynein regulators that bind both dynein and another dynein regulator Lis1 [51-55]. Lis1 can alter MT dynamics by reducing the catastrophe events of the MT plus ends [56, 57, 58]. Dynein also regulates disassembly of MT minus end in $\mathrm{M}$ phase [59]. We cloned Nudel in a yeast two-hybrid screen using mitosin kinetochore binding domains as bait (Figure 4) [53]. Mitosin binds Nudel at a region similar to the LEK1binding domain of NudE (Figure 4) [50]. However, as the NudE-binding domain of LEK1 is equivalent to residues 2598-2675 of mitosin, NudE and Nudel apparently bind different regions on mitosin (Figure 4). Human mitosin is mainly a nuclear protein in interphase $[1-3,19]$. Given the activity of cytLEK1 on MTs in interphase, however, mitosin may modulate MT dynamics through Nudel and NudE in mitosis after nuclear envelope breakdown and thus contributes to spindle organizations and functions. On the other hand, more lines of solid evidence are still required to support the existence of an endogenous cytoplasmic form of mouse mitosin in interphase. At least, the documented exogenous cytLEK1 [50] appears to still lack $\sim 500$ amino acids at its $\mathrm{N}$-terminus (Figure 2) and may thus behave merely as a dominant-negative mutant.

\section{Mitosin may have a role in maintenance of chromosome condensation}

An intriguing phenotype of mitosin/CENP-Fdepleted mitotic cells is the chromosome decondensation before anaphase onset [37, 38]. This occurs unlikely as a result of excess illumination during live cell microscopy since calibration has been done for the system [37]. Moreover, in other cases, mitotic cells arrested in $\mathrm{M}$ phase can be monitored in our system for hours without losing viability. In intact cells, mitosin/CENP-F is rapidly degraded at the end of mitosis [2, 12], coincident with the timing for nucleus reassembly which requires chromosome decondensation [60]. Therefore, mitosin may play a role in maintenance of chromosome condensation till its degradation at late $\mathrm{M}$ phase. Depleting mitosin by RNAi thus results in premature chromosome decondensation.

Although how mitosin exerts such a role still needs further investigation, there are several supporting clues. First, the homology to SMC class of chromosome segregation ATPase (Figure 2) supports a role of mitosin in chromosome structure. SMC family proteins are chromosomal ATPases involved in chromosome condensation and/or sister chromatid cohesion [61, 62]. Mitosin and its orthologs contain a conserved P-loop motif potentially for ATP-binding [17] and thus might represent a novel class of SMC proteins. Second, a mitosin deletion mutant lacking amino acid residues 2489-2901 exhibits chromosome localization as speckles of various sizes and numbers in mitotic CHO cells [28]. In interphase, overexpressing this mutant alters nuclear chromatin organization as well [28]. As endogenous mitosin is not seen on chromosomes, its association with chromosomes might be highly dynamic. Alternatively, it might regulate chromosome morphology through other SMC proteins.

\section{Mitosin is a negative regulator for transcription factor ATF4}

Mitosin may serve as a scaffold protein in interphase to sequester and/or activate certain transcription factors. The S- and G2-dependent expression of mitosin as a nuclear matrix protein implies roles in interphase [2, 3]. The nuclear matrix is actively involved in DNA replication, higher-order chromatin organization, and gene regulation. Some nuclear matrix proteins are implicated in transcriptional regulations [63-66]. Leucine zipper motifs usually mediate proteinprotein interactions in transcription factors [15, 67]. Our identification of ATF4 as a mitosin interactor is consistent with these speculations [68]. ATF4, also termed CREB2, is a member of the ATF/CREB family of basic leucine zipper (bZip) transcription factors and functions in cell proliferation, bone and lens differentiation, and stress response [69-76]. Through leucine zippers, ATF4 can dimerize with members either in the ATF/ CREB family including itself or in other bZip 
transcription factor families, such as c-Fos and c-Jun in AP-1 family [77-79].

Mitosin can downregulate ATF4 [68]. Overexpressing full-length mitosin suppresses the transactivation activity of ATF4, while depleting mitosin by RNAi strongly augments such activity. Mitosin interacts with a C-terminal region of ATF4 including the DNA-binding bZip domain in two-hybrid assays, implying a possibility to modulate the DNA-binding activity of ATF4. Consistently, in the presence of a mitosin mutant capable of binding ATF4 through a leucine zipper, ATF4 fails to bind DNA. In addition, mitosin also contains another ATF4-binding region whose association does not influence the DNA-binding of ATF4.

The mitosin-ATF4 interaction may have several physiological significances. First, the interaction may have a role in cell cycle progression. Cyclin A is essential for S phase progression and its gene transcription is largely stimulated by ATF/ CREB family members such as ATF2 and ATF3 in S phase [80, 81]. Moreover, association of ATF2 with Jun family transcription factors can further markedly stimulate the activities of Cyclin A promoter [80]. ATF4, however, inhibits the ATF2 activity on the promoter. Furthermore, ATF4 levels increase following the cell cycle progression into $S$ phase while ATF2 levels remain relatively constant [80]. Therefore, the increasing amount of mitosin in $\mathrm{S}$ phase may sequester ATF4 from the promoter, thereby allowing the more potent ATF2 and ATF3 to function. Consistent with this idea, mitosin does not interact with other ATF/CREB family members [68]. Second, mitosin may regulate ATF4 in other cellular activities such as stress response and differentiation $[71-74,76]$. These speculations, however, still need experimental supports.

\section{Mitosin has a role in differentiation through interaction with $\mathbf{R b}$}

Mitosin orthologs LEK1 and CMF1 function in muscle differentiation through interaction with $\mathrm{Rb}$ $[18,82]$. Mitosin, LEK1, and CMF1 bind $\mathrm{Rb}$ in vitro through a region homologous to that of $\mathrm{E} 2 \mathrm{~F} 1$ but different from the typical Rb-binding motif ("LXCXE") [3, 20, 21]. Coimmunoprecipitation of LEK1 with all three members of the pocket protein family, $\mathrm{Rb}, \mathrm{p} 107$, and $\mathrm{p} 130$, has been reported [20, 82]. Recently, the interaction between LEK1 and $\mathrm{Rb}$ has been shown to be critical for embryonic stem (ES) cell differentiation toward cardiac muscles [82]. Rb-deficient ES cells exhibit delays in cardiac differentiation similar to those with repressed LEK1 expression by RNAi. Moreover, disrupting the Rb-LEK1 interaction specifically by overexpressing a nuclear form of the Rb-binding domain of LEK1 also causes similar retardation. As a result, transcription levels for genes downstream of the bone morphogenetic protein (BMP) pathway and critical for cardiac differentiation [83, 84], for instances, Nkx2.5 and Mef2c, are significantly down-regulated [82]. Activation of the BMP-dependent pathway rescues the defects in both gene expression and cardiac differentiation, placing Rb and LEK1 in a BMPindependent pathway [82]. It is known that $\mathrm{Rb}$ binds many transcription factors and modulates their activities either positively or negatively in cell cycle or differentiation [6, 7, 85-87]. Mitosin orthologs, on the other hand, may bind and regulate multiple transcription factors as well, with ATF4 as an example [68]. Interaction of mitosin with $\mathrm{Rb}$ may exert mutual influences on activities of their associated transcription factors and thus modulate cell fates.

\section{Acknowledgements}

This work was supported by Grants No. 30330330 and 30421005 from Natural Science Foundation of China.

\section{References}

1. Rattner J.B., Rao A., Fritzler M.J., Valencia D.W. and Yen T.J., CENP-F is a ca. $400 \mathrm{kDa}$ kinetochore protein that exhibits a cell-cycle dependent localization. Cell Motil. Cytoskeleton 26(3): 214-226, 1993.

2. Liao H., Winkfein R.J., Mack G., Rattner J.B. and Yen T.J., CENP-F is a protein of the nuclear matrix that assembles onto kinetochores at late G2 and is rapidly degraded after mitosis. J. Cell Biol. 130(3): 507-518, 1995.

3. Zhu X., Mancini M.A., Chang K.H., Liu C.Y., Chen C.F., Shan B., Jones D., Yang-Feng T.L. and Lee W.H., Characterization of a novel 350-kilodalton nuclear phosphoprotein that is specifically involved in mitotic-phase progression. Mol. Cell Biol. 15(9): 5017-5029, 1995.

4. Shan B., Zhu X., Chen P.L., Durfee T., Yang Y., Sharp D. and Lee W.H., Molecular cloning of cellular genes encod- 
ing retinoblastoma-associated proteins: identification of a gene with properties of the transcription factor E2F. Mol. Cell Biol. 12(12): 5620-5631, 1992.

5. Laoukili J., Kooistra M.R., Bras A., Kauw J., Kerkhoven R.M., Morrison A., Clevers H. and Medema RH., FoxM1 is required for execution of the mitotic programme and chromosome stability. Nat. Cell Biol. 7(2): 126-136, 2005.

6. Chau B.N. and Wang J.Y., Coordinated regulation of life and death by RB. Nat. Rev. Cancer 3(2): 130-138, 2003.

7. Zheng L. and Lee W.H., The retinoblastoma gene: a prototypic and multifunctional tumor suppressor. Exp. Cell Res. 264(1): 2-18, 2001.

8. Shigeishi H., Mizuta K., Higashikawa K., Yoneda S., Ono S. and Kamata N., Correlation of CENP-F gene expression with tumor-proliferating activity in human salivary gland tumors. Oral Oncol. 41(7): 716-722, 2005.

9. de la Guardia C., Casiano C.A., Trinidad-Pinedo J. and Baez A., CENP-F gene amplification and overexpression in head and neck squamous cell carcinomas. Head Neck 23(2): 104-112, 2001

10. Erlanson M., Casiano C.A., Tan E.M., Lindh J., Roos G. and Landberg G., Immunohistochemical analysis of the proliferation associated nuclear antigen CENP-F in nonHodgkin's lymphoma. Mod. Pathol. 12(1): 69-74, 1999.

11. Rattner J.B., Rees J., Whitehead C.M., Casiano C.A., Tan E.M., Humbel R.L., Conrad K. and Fritzler M.J., High frequency of neoplasia in patients with autoantibodies to centromere protein CENP-F. Clin. Invest. Med. 20(5): 308319, 1997.

12. Zhu X., Chang K.H., He D., Mancini M.A., Brinkley W.R. and Lee W.H., The C terminus of mitosin is essential for its nuclear localization, centromere/kinetochore targeting, and dimerization. J. Biol. Chem. 270(33): 19545-19550, 1995.

13. Ashar H.R., James L., Gray K., Carr D., Black S., Armstrong L., Bishop W.R. and Kirschmeier P., Farnesyl transferase inhibitors block the farnesylation of CENP-E and CENP-F and alter the association of CENP-E with the microtubules. J. Biol. Chem. 275(39): 30451-30457, 2000.

14. Hussein D. and Taylor S.S., Farnesylation of Cenp-F is required for $\mathrm{G} 2 / \mathrm{M}$ progression and degradation after mitosis. J. Cell Sci. 115(Pt 17): 3403-3414, 2002.

15. Landschulz W.H., Johnson P.F. and McKnight S.L., The leucine zipper: a hypothetical structure common to a new class of DNA binding proteins. Science 240(4860): 17591764, 1988.

16. Wei Y., Bader D. and Litvin J., (1996). Identification of a novel cardiac-specific transcript critical for cardiac myocyte differentiation. Development 122(9): 2779-2789, 1996.

17. Goodwin R.L., Pabon-Pena L.M., Foster G.C. and Bader D., The cloning and analysis of LEK1 identifies variations in the LEK/centromere protein $\mathrm{F} /$ mitosin gene family. J. Biol. Chem. 274(26): 18597-18604, 1999.

18. Pabon-Pena L.M., Goodwin R.L., Cise L.J. and Bader D., Analysis of CMF1 reveals a bone morphogenetic proteinindependent component of the cardiomyogenic pathway. J. Biol. Chem. 275(28): 21453-21459, 2000.

19. Yang Z., Guo J., Li N., Qian M., Wang S. and Zhu X., Mitosin/CENP-F is a conserved kinetochore protein subjected to cytoplasmic dynein-mediated poleward transport. Cell Res. 13(4): 275-283, 2002.

20. Ashe M., Pabon-Pena L., Dees E., Price K.L. and Bader D., LEK1 is a potential inhibitor of pocket proteinmediated cellular processes. J. Biol. Chem. 279(1): 664676, 2004.
21. Redkar A., deRiel J.K., Xu Y.S., Montgomery M., Patwardhan V. and Litvin J., Characterization of cardiac muscle factor 1 sequence motifs: retinoblastoma protein binding and nuclear localization. Gene 282(1-2): 53-64, 2002.

22. Dees E., Pabon-Pena L.M., Goodwin R.L. and Bader D., Characterization of CMF1 in avian skeletal muscle. Dev. Dyn. 219(2): 169-181, 2000.

23. Cleveland D.W., Mao Y. and Sullivan K.F., Centromeres and kinetochores: from epigenetics to mitotic checkpoint signaling. Cell 112(4): 407-421, 2003.

24. Biggins S. and Walczak C.E., Captivating capture: how microtubules attach to kinetochores. Curr. Biol. 13(11): R449-460, 2003.

25. Maiato H., DeLuca J., Salmon E.D. and Earnshaw W.C., The dynamic kinetochore-microtubule interface. J. Cell Sci. 117(Pt 23): 5461-5477, 2004.

26. Rieder C.L. and Salmon E.D., The vertebrate cell kinetochore and its roles during mitosis. Trends Cell Biol. 8(8): 310-318, 1998.

27. Musacchio A. and Hardwick K.G., The spindle checkpoint: structural insights into dynamic signalling. Nat. Rev. Mol. Cell Biol. 3(10): 731-741, 2002.

28. Zhu X., Structural requirements and dynamics of mitosinkinetochore interaction in M phase. Mol. Cell Biol. 19(2): 1016-1024, 1999.

29. Johnson V.L., Scott M.I., Holt S.V., Hussein D. and Taylor S.S., Bubl is required for kinetochore localization of BubR1, Cenp-E, Cenp-F and Mad2, and chromosome congression. J. Cell Sci. 117(Pt 8): 1577-1589, 2004.

30. Liu S.T., Hittle J.C., Jablonski S.A., Campbell M.S., Yoda K. and Yen T.J., Human CENP-I specifies localization of CENP-F, MAD1 and MAD2 to kinetochores and is essential for mitosis. Nat. Cell Biol. 5(4): 341-345, 2003.

31. Salina D., Enarson P., Rattner J.B. and Burke B., Nup358 integrates nuclear envelope breakdown with kinetochore assembly. J. Cell Biol. 162(6): 991-1001, 2003.

32. Wang H., Hu X., Ding X., Dou Z., Yang Z., Shaw A.W., Teng M., Cleveland D.W., Goldberg M.L., Niu L. et al., Human Zwint-1 specifies localization of Zeste White 10 to kinetochores and is essential for mitotic checkpoint signaling. J. Biol. Chem. 279(52): 54590-54598, 2004.

33. Steensgaard P., Garre M., Muradore I., Transidico P., Nigg E.A., Kitagawa K., Earnshaw W.C., Faretta M. and Musacchio A., Sgt1 is required for human kinetochore assembly. EMBO Rep. 5(6): 626-631, 2004.

34. Joseph J., Liu S.T., Jablonski S.A., Yen T.J. and Dasso M., The RanGAP1-RanBP2 complex is essential for microtubule-kinetochore interactions in vivo. Curr. Biol. 14(7): 611-617, 2004.

35. Howell B.J., McEwen B.F., Canman J.C., Hoffman D.B., Farrar E.M., Rieder C.L. and Salmon E.D., Cytoplasmic dynein/dynactin drives kinetochore protein transport to the spindle poles and has a role in mitotic spindle checkpoint inactivation. J. Cell Biol. 155(7): 1159-1172, 2001.

36. Bomont P., Maddox P., Shah J.V., Desai A.B. and Cleveland D.W., Unstable microtubule capture at kinetochores depleted of the centromere-associated protein CENP-F. Embo. J. 24(22), 3927-3939, 2005.

37. Yang Z., Guo J., Chen Q., Ding C., Du J. and Zhu X., Silencing mitosin induces misaligned chromosomes, premature chromosome decondensation before anaphase onset, and mitotic cell death. Mol. Cell Biol. 25(10): 4062-4074, 2005. 
38. Holt S.V., Vergnolle M.A., Hussein D., Wozniak M.J., Allan V.J. and Taylor S.S., Silencing Cenp-F weakens centromeric cohesion, prevents chromosome alignment and activates the spindle checkpoint. J. Cell Sci. 118(Pt 20): 4889-4900, 2005.

39. Rieder C.L. and Maiato H., Stuck in division or passing through: what happens when cells cannot satisfy the spindle assembly checkpoint. Dev. Cell 7(5): 637-651, 2004.

40. Cimini D., Moree B., Canman J.C. and Salmon E.D., Merotelic kinetochore orientation occurs frequently during early mitosis in mammalian tissue cells and error correction is achieved by two different mechanisms. J. Cell Sci. 116(Pt 20): 4213-4225, 2003.

41. Cimini D., Cameron L.A. and Salmon E.D., Anaphase spindle mechanics prevent mis-segregation of merotelically oriented chromosomes. Curr. Biol. 14(23): 2149-2155, 2004.

42. Lampson M.A., Renduchitala K., Khodjakov A. and Kapoor T.M., Correcting improper chromosome-spindle attachments during cell division. Nat. Cell Biol. 6(3): 232237, 2004.

43. Gorbsky G.J., Mitosis: MCAK under the aura of Aurora B. Curr. Biol. 14(9): R346-R348, 2004.

44. Kline-Smith S.L., Khodjakov A., Hergert P. and Walczak C.E., Depletion of centromeric MCAK leads to chromosome congression and segregation defects due to improper kinetochore attachments. Mol. Biol. Cell 15(3): 1146-1159, 2004.

45. Chan G.K., Schaar B.T. and Yen T.J., Characterization of the kinetochore binding domain of CENP-E reveals interactions with the kinetochore proteins CENP-F and hBUBR1. J. Cell Biol. 143(1): 49-63, 1998.

46. Yao X., Abrieu A., Zheng Y., Sullivan K.F. and Cleveland D.W., CENP-E forms a link between attachment of spindle microtubules to kinetochores and the mitotic checkpoint. Nat. Cell Biol. 2(8): 484-491, 2000.

47. Schaar B.T., Chan G.K., Maddox P., Salmon E.D. and Yen T.J., CENP-E function at kinetochores is essential for chromosome alignment. J. Cell Biol. 139(6): 1373-1382, 1997.

48. McEwen B.F., Chan G.K., Zubrowski B., Savoian M.S., Sauer M.T. and Yen T.J., CENP-E is essential for reliable bioriented spindle attachment, but chromosome alignment can be achieved via redundant mechanisms in mammalian cells. Mol. Biol. Cell 12(9): 2776-2789, 2001.

49. Hoffman D.B., Pearson C.G., Yen T.J., Howell B.J. and Salmon E.D., Microtubule-dependent changes in assembly of microtubule motor proteins and mitotic spindle checkpoint proteins at PtK1 kinetochores. Mol. Biol. Cell 12(7): 1995-2009, 2001.

50. Soukoulis V., Reddy S., Pooley R.D., Feng Y., Walsh C.A. and Bader D.M., Cytoplasmic LEK1 is a regulator of microtubule function through its interaction with the LIS1 pathway. Proc. Natl. Acad. Sci. USA 102(24): 8549-8554, 2005.

51. Liang Y., Yu W., Li Y., Yang Z., Yan X., Huang Q. and Zhu X., Nudel functions in membrane traffic mainly through association with Lis1 and cytoplasmic dynein. J. Cell Biol. 164(4): 557-566, 2004.

52. Sasaki S., Shionoya A., Ishida M., Gambello M.J., Yingling J., Wynshaw-Boris A. and Hirotsune S., A LIS1/NUDEL/cytoplasmic dynein heavy chain complex in the developing and adult nervous system. Neuron 28(3): 681-696, 2000.

53. Yan X., Li F., Liang Y., Shen Y., Zhao X., Huang Q. and Zhu X., Human Nudel and NudE as regulators of cytoplasmic dynein in poleward protein transport along the mitotic spindle. Mol. Cell Biol. 23(4): 1239-1250, 2003.

54. Feng Y., Olson E.C., Stukenberg P.T., Flanagan L.A., Kirschner M.W. and Walsh C.A., LIS1 regulates CNS lamination by interacting with $\mathrm{mNudE}$, a central component of the centrosome. Neuron 28(3): 665-679, 2000.

55. Feng Y. and Walsh C.A., Mitotic spindle regulation by Ndel controls cerebral cortical size. Neuron 44(2): 279293, 2004.

56. Xiang X., LIS1 at the microtubule plus end and its role in dynein-mediated nuclear migration. J. Cell Biol. 160(3): 289-290, 2003.

57. Faulkner N.E., Dujardin D.L., Tai C.Y., Vaughan K.T., O'Connell C.B., Wang Y. and Vallee R.B., A role for the lissencephaly gene LIS1 in mitosis and cytoplasmic dynein function. Nat. Cell Biol. 2(11): 784-791, 2000.

58. Sapir T., Elbaum M. and Reiner O., Reduction of microtubule catastrophe events by LIS1, platelet-activating factor acetylhydrolase subunit. Embo. J. 16(23): 69776984, 1997.

59. Gaetz J. and Kapoor T.M., Dynein/dynactin regulate metaphase spindle length by targeting depolymerizing activities to spindle poles. J. Cell Biol. 166(4): 465-471, 2004.

60. Rieder C.L. and Khodjakov A., Mitosis through the microscope: advances in seeing inside live dividing cells. Science 300(5616): 91-96, 2003.

61. Legagneux V., Cubizolles F. and Watrin E., Multiple roles of Condensins: a complex story. Biol. Cell 96(3): 201-213, 2004.

62. Hirano T., Condensins: organizing and segregating the genome. Curr. Biol. 15(7): R265-275, 2005.

63. Bidwell J.P., Alvarez M., Feister H., Onyia J. and Hock J., Nuclear matrix proteins and osteoblast gene expression. J. Bone Miner. Res. 13(2): 155-167, 1998.

64. Loidl P. and Eberharter A., Nuclear matrix and the cell cycle. Int. Rev. Cytol. 162B: 377-403, 1995.

65. Davie J.R., Nuclear matrix, dynamic histone acetylation and transcriptionally active chromatin. Mol. Biol. Rep. 24(3): 197-207, 1997

66. Stein G.S., Zaidi S.K., Braastad C.D., Montecino M., van Wijnen A.J., Choi J.Y., Stein J.L., Lian J.B. and Javed A., Functional architecture of the nucleus: organizing the regulatory machinery for gene expression, replication and repair. Trends Cell Biol. 13(11): 584-592, 2003.

67. O'Shea E.K., Rutkowski R., Stafford W.F. and Kim P.S., Preferential heterodimer formation by isolated leucine zippers from fos and jun. Science 245(4918): 646-648, 1989.

68. Zhou X., Wang R., Fan L., Li Y, Ma L., Yang Z., Yu W., Jing N. and Zhu X., Mitosin/CENP-F as a negative regulator of activating transcription factor-4. J. Biol. Chem. 280(14): 13973-13977, 2005.

69. Hai T. and Hartman M.G., The molecular biology and nomenclature of the activating transcription factor/cAMP responsive element binding family of transcription factors: activating transcription factor proteins and homeostasis. Gene 273(1): 1-11, 2001

70. Siu F., Bain P.J., LeBlanc-Chaffin R., Chen H. and Kilberg M.S., ATF4 is a mediator of the nutrient-sensing response pathway that activates the human asparagine synthetase gene. J. Biol. Chem. 277(27): 24120-24127, 2002.

71. Harding H.P., Zhang Y., Zeng H., Novoa I., Lu P.D., Calfon M., Sadri N., Yun C., Popko B., Paules R. et al., An integrated stress response regulates amino acid metabolism 
and resistance to oxidative stress. Mol. Cell 11(3): 619-633, 2003.

72. Rutkowski D.T. and Kaufman R.J., All roads lead to ATF4. Dev. Cell 4(4): 442-444, 2003.

73. Tanaka T., Tsujimura T., Takeda K., Sugihara A., Maekawa A., Terada N., Yoshida N. and Akira S., Targeted disruption of ATF4 discloses its essential role in the formation of eye lens fibres. Genes Cells 3(12): 801-810, 1998.

74. Masuoka H.C. and Townes T.M., Targeted disruption of the activating transcription factor 4 gene results in severe fetal anemia in mice. Blood 99(3): 736-745, 2002.

75. Hettmann T., Barton K. and Leiden J.M., Microphthalmia due to p53-mediated apoptosis of anterior lens epithelial cells in mice lacking the CREB-2 transcription factor. Dev. Biol. 222(1): 110-123, 2000.

76. Yang X., Matsuda K., Bialek P., Jacquot S., Masuoka H.C., Schinke T., Li L., Brancorsini S., Sassone-Corsi P., Townes T.M. et al., ATF4 is a substrate of RSK2 and an essential regulator of osteoblast biology; implication for Coffin-Lowry Syndrome. Cell 117(3): 387-398, 2004.

77. Hai T.W., Liu F., Coukos W.J. and Green M.R., Transcription factor ATF cDNA clones: an extensive family of leucine zipper proteins able to selectively form DNAbinding heterodimers. Genes Dev. 3(12B): 2083-2090, 1989.

78. Hai T. and Curran T., Cross-family dimerization of transcription factors Fos/Jun and ATF/CREB alters DNA binding specificity. Proc. Natl. Acad. Sci. USA 88(9): 3720-3724, 1991.

79. Kato Y., Koike Y., Tomizawa K., Ogawa S., Hosaka K., Tanaka S. and Kato T., Presence of activating transcription factor 4 (ATF4) in the porcine anterior pituitary. Mol. Cell Endocrinol. 154(1-2): 151-159, 1999.
80. Shimizu M., Nomura Y., Suzuki H., Ichikawa E., Takeuchi A., Suzuki M., Nakamura T., Nakajima T. and Oda K., Activation of the rat cyclin A promoter by ATF2 and Jun family members and its suppression by ATF4. Exp. Cell Res. 239(1): 93-103, 1998.

81. Desdouets C., Matesic G., Molina C.A., Foulkes N.S., Sassone-Corsi P., Brechot C. and Sobczak-Thepot J., Cell cycle regulation of cyclin A gene expression by the cyclic AMP-responsive transcription factors CREB and CREM. Mol. Cell Biol. 15(6): 3301-3309, 1995.

82. Papadimou E., Menard C., Grey C. and Puceat M., Interplay between the retinoblastoma protein and LEK1 specifies stem cells toward the cardiac lineage. EMBO J. 24(9): 1750-1761, 2005.

83. Srivastava D. and Olson E.N., A genetic blueprint for cardiac development. Nature 407(6801): 221-226, 2000.

84. Olson E.N. and Schneider M.D., Sizing up the heart: development redux in disease. Genes Dev. 17(16): 1937 1956, 2003.

85. Chen P.L., Riley D.J., Chen Y. and Lee W.H., Retinoblastoma protein positively regulates terminal adipocyte differentiation through direct interaction with C/EBPs. Genes Dev. 10(21): 2794-2804, 1996.

86. Chen P.L., Riley D.J. and Lee W.H., The retinoblastoma protein as a fundamental mediator of growth and differentiation signals. Crit. Rev. Eukaryot. Gene Expr. 5(1): 7995, 1995.

87. Nguyen D.X. and McCance D.J., Role of the retinoblastoma tumor suppressor protein in cellular differentiation. J. Cell Biochem. 94(5): 870-879, 2005. 